\title{
11. THE NUMERICAL PALLOGRAPH EXPERIMENT: PRECISE MEASUREMENT OF THE HEAVE, PITCH, AND ROLL OF JOIDES RESOLUTION ${ }^{1}$
}

\author{
O. Besancon ${ }^{2}$ and J. Guesnon ${ }^{2}$
}

\section{OBJECTIVES OF THE EXPERIMENT}

The study of deep-water risers and ocean-mining pipes, for depths exceeding 2000 and $5000 \mathrm{~m}$, respectively, has revealed problems relating to dynamic behavior that do not occur at lesser depths. When a riser is hung off a drillship, the heave of the ship induces axial dynamic forces in the riser. In deep water these can become very large and even lead to buckling and failure of the riser. These forces must be studied carefully and taken into account by the riser designer. Their magnitudes depend on the following factors:

1. The total mass of the hung-off riser, including buoyancy modules, peripheral liner, etc.

2. The natural frequencies of axial vibration of the riser.

3. The ship heave excitation.

Long risers are subjected to large forces, first, because their mass is inevitably large, and second, because their natural periods, which are a function of length, start approaching the wave active zone. They can theoretically be as high as $6 \mathrm{~s}$. This can lead to large dynamic amplification, if not to actual axial resonance.

The theoretical behavior of the riser can be accurately calculated once the top end heave excitation is known. But then, drillship heave response at the critical short periods (below about $7 \mathrm{~s}$ ) is very imprecisely known.

The objective of the "numerical pallograph" experiment is therefore aimed at obtaining this information as accurately as possible by measuring the movements of the JOIDES Resolution as she cruises the Earth's oceans.

The experiment has been mounted and financed jointly by the Institut Français du Pétrole (IFP), GEMONOD, and the Institut Français de Recherche pour l'Exploitation de la Mer (IFREMER) with the following immediate objectives:

1. To create a database of the movements of a typical, large, dynamically positioned drillship.

2. To process the data acquired and use them in the analysis of the dynamic behavior of deep-water risers subjected to possible resonance and fatigue.

\section{PRESENTATION OF THE EXPERIMENT}

The experiment can be divided into four parts, of which the first has been completed. The second and third parts are in progress at present, and the fourth will be attempted shortly.

1. Design, manufacture, and calibration of the central processor (the actual pallograph).

\footnotetext{
${ }^{1}$ Harding, B. W., Storms, M. A., et al., 1990. Proc. ODP, Init. Repts., 124E: College Station, TX (Ocean Drilling Program).

2 Institut Français du Pétrole, 1 and 4 av. de Bois-Preau BP 311, 92506 Rueil Malmaison Cedex, France.
}

2. Raw-data acquisition on board.

3. Data processing, computation of ship's movements, and compilation of a data base.

4. Selection of representative sequences for the analysis of three typical applications: (1) a 3000-m drilling riser, (2) $5000 \mathrm{~m}$ of ocean-mining pipe, and (3) drill string for geological samplings used by ODP.

\section{Central Processor}

The central processor is highly sensitive. It is designed to measure low-amplitude, short-period movements with high accuracy. It consists of:

1. Two servo-accelerometers and two inclinometers, allowing data acquisition principally of heave, roll, and pitch, and, with lower accuracy, surge.

2. Digital-acquisition electronics, for one synchronized measurement every $0.35 \mathrm{~s}$, during the 47 -min sequence initiated systematically at 2 -hr intervals.

3. A magnetic tape recorder.

The central processor (see Fig. 1) was installed on board the JOIDES Resolution, in the upper 'tween deck on the transverse axis of the ship, in February 1988 during her port call at Fremantle (Western Australia). During Legs 120, 121, and 122, 1000 sequences of about $45 \mathrm{~min}$ each were recorded. However, analysis of the first measurements revealed unexpected calibration problems, which led to the return of the unit to France in late 1988 and accordingly delayed the first analyses. The central processor was then reinstalled on board in January 1989 in Ma-

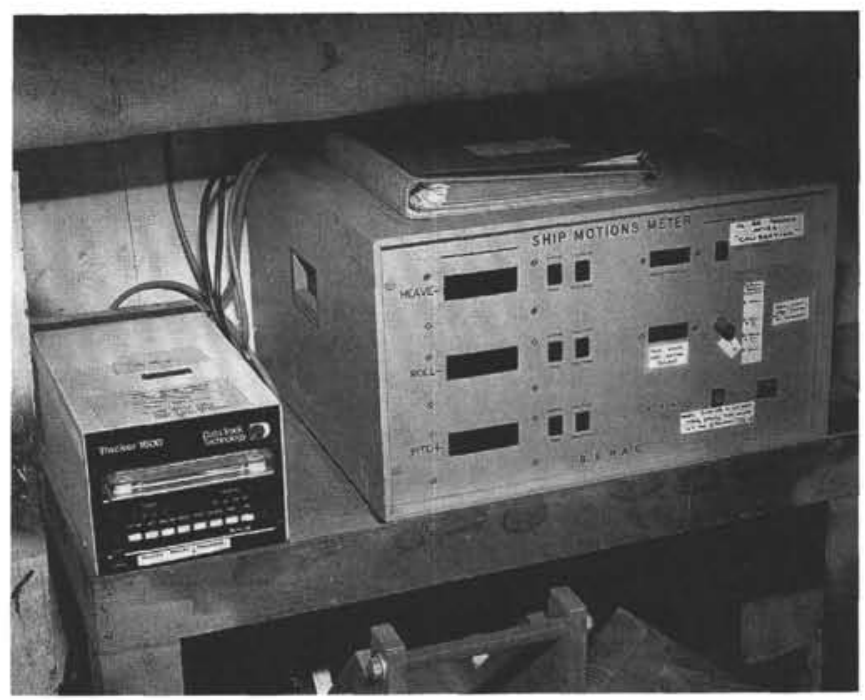

Figure 1. Pallograph installed on board JOIDES Resolution. 
nila (Philippines). A more accurate and more reliable calibration procedure was tested successfully.

\section{On-Board Data Acquisition}

The unit was automated to the extent possible so as to require a minimum number of operations during the planned 2 years of data acquisition. Once daily, the recording cassette is replaced and the operation of the instrument checked. At the start of each survey, calibration is carried out in port to identify any possible evolution in the sensitivity of the instruments. At the end of each drilling leg, the recorded cassettes are sent to France for analysis.

\section{Data Processing}

Software, in the course of validation, is designed to determine at all times the actual movements of the ship in a fixed location from the raw data gathered from the four sensors. The converted data will be processed by conventional statistical methods.

\section{Selection of Representative Sequences}

This selection will be carried out using software products already developed by IFREMER and IFP for riser design. A simple program will be used for the preliminary selection. A more sophisticated program (finite elements) will then be used for the detailed selection and for the study of the actual behavior of the riser, ocean-mining pipe, and ODP drill string.

\section{REPORT ON PRELIMINARY DATA}

In view of the problems listed in the section on the central processor, the recordings made in 1988 have not yet been systematically processed. However, the processing of some of them enabled us to confirm the validity of the acquisition method, the reliability of the hardware, and the usefulness of the measurements obtained. The usefulness will be enhanced when more recordings are made.

As an example, the curves shown in Figure 2 were obtained using still-uncertain calibration coefficients from recordings made on 11 March 1988 at $1600 \mathrm{hr}$ or 4:00 p.m. (GMT or UTC). The sea conditions entered in the ship's log were as follows:

1. Wave direction: $310^{\circ}$.

2. Significant height: $6 \mathrm{~m}$.

3. Ship's heading: $310^{\circ}$ (probably) (Leg 120 , lat. $54^{\circ} 48^{\prime} \mathrm{S}$, long. $76^{\circ} 47^{\prime} \mathrm{E}$, south of the Kerguelen Islands).

The following points can be noted:

1. The high acquisition accuracy, which allows good-quality "reconstruction" of the ship's movements.

2. The numerical character of this acquisition, which leads to accurate spectra and allows subsequent treatment of these data in highly economical conditions.

3. The large-amplitude pitch on this date.

\section{CONCLUSIONS}

The work carried out on board the JOIDES Resolution served to initiate successfully the "numerical pallograph" experiment, which entered a purely operational acquisition phase in early 1989. This joint IFP/IFREMER/GEMONOD experiment will, thanks to ODP, supply extremely useful information for the design of future deep-water drilling risers and ocean-mining systems.

\section{Ms 124E-111}


A
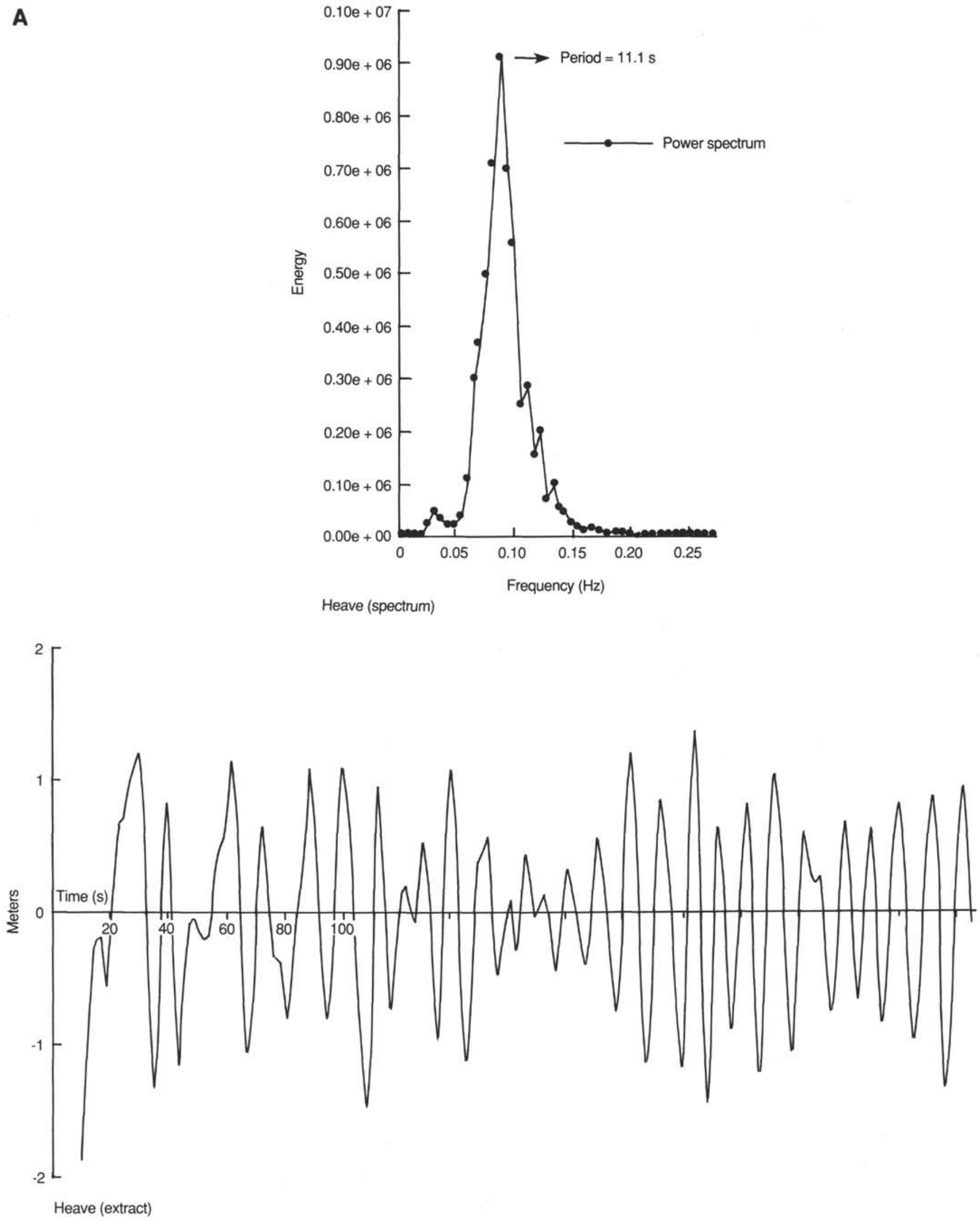

Figure 2. Pallograph recordings made on 11 March 1988 at $1600 \mathrm{hr}$, illustrating various aspects of ship's motion. A. Heave. B. Roll and pitch. 
O. BESANCON, J. GUESNON
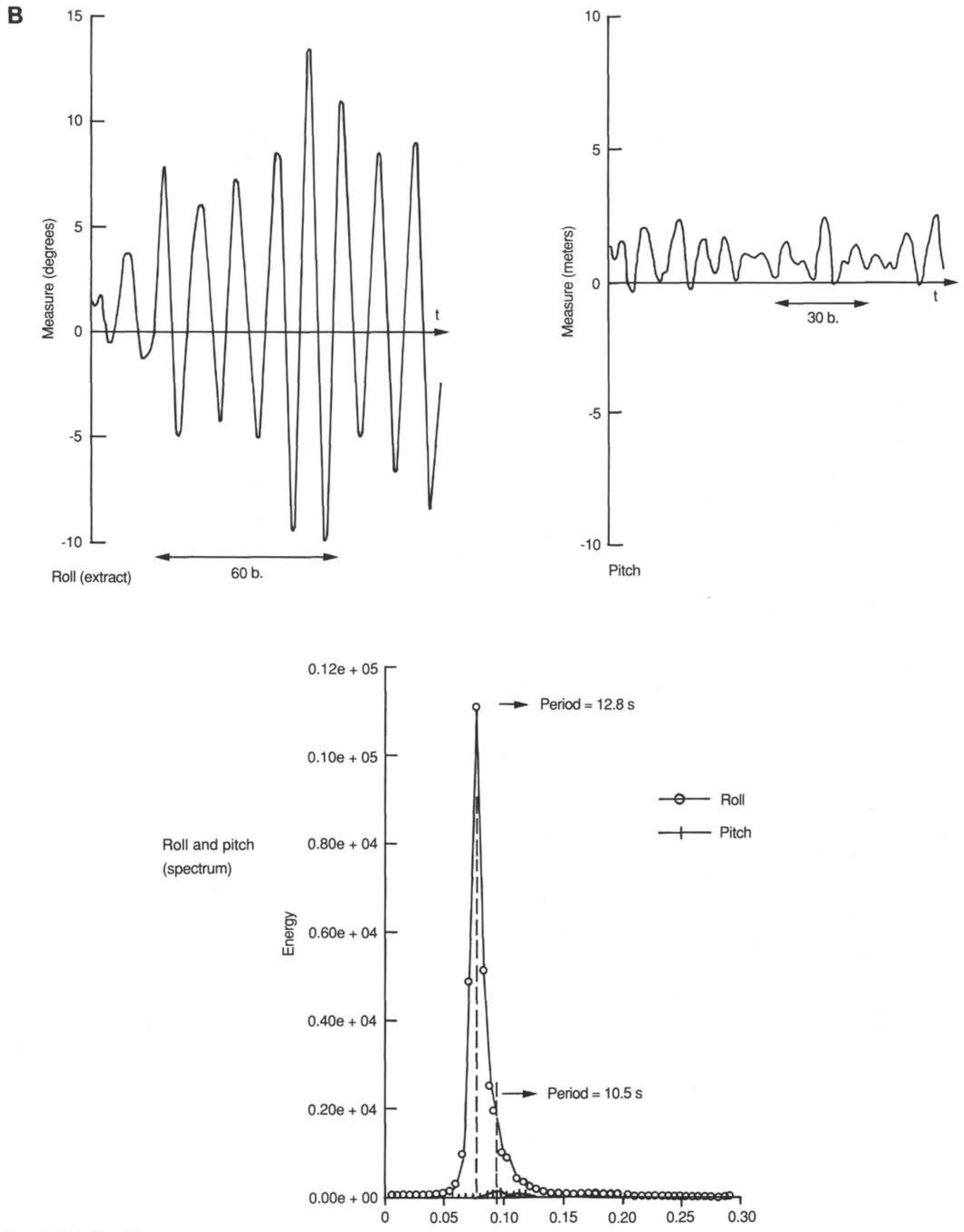

Figure 2 (continued). 